\title{
Interleukin-10 in the Pathophysiology of Inflammatory Bowel Disease: Increased Serum Concentrations During the Recovery Phase
}

\author{
Keiichi Mitsuyama, Nobuo Tomiyasu, Kosuke Takaki, Junya Masuda, Hiroshi Yamasaki, Kotaro Kuwaki, \\ Teiko Takeda, Shigehiko Kitazaki, Osamu Tsuruta, and Michio Sata
}

Division of Gastroenterology, Department of Medicine, Kurume University School of Medicine, Asahi-machi 67, Kurume 830-0011, Japan

Received 19 June 2006; Revised 10 August 2006; Accepted 10 August 2006

\begin{abstract}
Using a specific enzyme-linked immunosorbent assay, IL-10 concentrations were measured in serum from 62 patients with ulcerative colitis (UC), 43 with Crohn's disease (CD), 25 with other colitides, and 44 normal control subjects. Serum IL-10 concentrations were increased in patients with active UC but not in those with active CD when compared with normal control subjects. A time course study showed that in patients with UC and CD, serum concentrations of IL- 6 and C-reactive protein increased during the acute phase and returned to normal as patients go into remission. Notably, serum IL-10 concentrations increased during the phase of disease resolution and declined thereafter regardless of the treatment modality. Gel filtration analysis indicated that IL-10 circulated predominantly as a dimer. In conclusion, this study shows that serum IL-10 is increased during disease recovery in patients with inflammatory bowel disease, and may be a helpful marker in monitoring disease status.
\end{abstract}

Copyright ( 92006 Keiichi Mitsuyama et al. This is an open access article distributed under the Creative Commons Attribution License, which permits unrestricted use, distribution, and reproduction in any medium, provided the original work is properly cited.

\section{INTRODUCTION}

The cause of ulcerative colitis (UC) and Crohn's disease (CD) is unclear. It remains to be determined whether these diseases represent an abnormal response to normal antigenic stimuli or an appropriate response to persistently abnormal stimuli $[1,2]$. However, it is now well accepted that several cytokines with proinflammatory activities, including interleukin (IL)1, IL-6, IL-8, IL-12, and tumor necrosis factor (TNF)- $\alpha$, are upregulated in inflammatory bowel disease (IBD) and play a key role in the clinical and immunopathological manifestations of the disease [3-6].

IL-10 is an immunoregulatory cytokine that strongly downregulates the production of proinflammatory cytokines and Thelper 1 cytokines [7-12]. Of particular interest are the data on IL-10 deficient mice by Kuhn et al, showing chronic noninfectious intestinal inflammation [13]. This finding corroborates the action of IL-10 against chronic stimulation of the intestinal immune system. It has also been demonstrated that an elevated production of proinflammatory cytokines by IBD mononuclear cells could be downregulated in vitro by external IL-10, and also in vivo with topical IL-10 enema preparations [14]. This indicates that the intrinsic intestinal bioactivity of IL-10 may be insufficient to control intestinal inflammation. Therefore, recognition of this cytokine will provide a new dimension to understanding the pathophysiology of IBD.

In the present study, we identified and quantitated the serum IL-10 in patients with IBD using a specific and sensitive enzyme-linked immunosorbent assay (ELISA) and examined the relationship of serum IL-10 to the proinflammatory cytokine IL- 6 and other clinical parameters.

\section{MATERIALS AND METHODS}

\section{Patients and control subjects}

Blood samples were collected from 62 patients with UC (median age: 33.9 years; 37 male, 25 females) and 43 with CD (median age: 29.4 years; 29 males, 14 females) defined according to the characteristic clinical, endoscopic, radiologic, and histologic criteria. The severity of active UC was specified according to the criteria of Truelove and Witts as mild, moderate, or severe [15]. Only those patients who were classified as fully in remission were regarded as having inactive UC. Disease activity of CD was assessed according to 
scores established by the International Organization for the Study of Inflammatory Bowel Disease (IOIBD). A score of 0 to 1 was considered to be inactive disease, whereas a score of 2 or greater was classified as active disease [16]. Previous work has shown a significant correlation between the IOIBD score and the Crohn's disease activity index (CDAI) [17]. In terms of disease distribution of UC, 45 patients had pancolitis, 10 had left colon involvement, and seven had disease limited to the distal colon. In the CD group, 26 patients had disease that affected both the ileum and colon, 11 had disease that affected the colon, and six had disease that affected the ileum. The patients were receiving the following treatments at the time of study: oral prednisolone only, $\mathrm{UC}=2, \mathrm{CD}=2 ; 5$-aminosalicylate only, $\mathrm{UC}=18, \mathrm{CD}=$ 16; both prednisolone and 5-aminosalicylate, $\mathrm{UC}=17, \mathrm{CD}$ $=10$; and no specific treatment, $\mathrm{UC}=25, \mathrm{CD}=18$. Samples were also obtained from 25 patients with other forms of intestinal inflammation, including 20 with infectious colitis and five with ischemic colitis, and from 44 healthy volunteers of similar age range and sex distribution as the IBD patients. Informed consent was given by every participant. The study protocol conformed to the Declaration of Helsinki and was approved by the local medical ethics committee.

\section{IL-10 ELISA}

An ELISA sensitive for IL-10 was developed by modifying a procedure based on the general principles for luminescence sandwich ELISA (Sumitomo Metal Bio-Science, Inc, Kanagawa, Japan) [18]. To briefly summarize the procedure, 96well microtiter plates (Microlite 2, Dynatech Laboratories Inc, Chantilly, Va, USA) were coated overnight at $4^{\circ} \mathrm{C}$ with $100 \mu \mathrm{L} /$ well of the anti-IL-10 monoclonal antibody JES9D7 [19] (final concentration, $1 \mu \mathrm{g} / \mathrm{mL}$; BD PharMingen, San Diego, Calif, USA). Plates were washed with $0.05 \%$ Tween 20/Tris-buffered saline. The plates were blocked with $250 \mu \mathrm{L}$ of $1 \%$ bovine serum albumin/Tris-buffered saline at room temperature for 2 hours and then were washed. One hundred microliters of sample and $50 \mu \mathrm{L}$ of $0.05 \%$ Tween $20 / 1 \%$ bovine serum albumin/Tris-buffered saline were added to each well and incubated overnight at $4^{\circ} \mathrm{C}$, and a standard for IL-10 was run concurrently. Plates were washed, and $100 \mu \mathrm{L}$ of biotinylated anti-IL-10 monoclonal antibody JES312G8 [19] (final concentration, $1 \mu \mathrm{g} / \mathrm{mL}$; BD PharMingen) was added to each well and incubated for 2 hours at room temperature. Plates were then washed and incubated with streptavidin/alkaline phosphatase conjugate (Bethesda Research Laboratories, Gaithersburg, Md, USA) at a dilution of $1: 6000$ for 30 minutes at room temperature. After washing again, LUMI-PHOS (Lumigen, Inc, Detroit, Mich, USA) was added to each well. Luminescence intensity was measured using a luminescence reader (MLR100, Corona Electric, Tokyo, Japan). The sensitivity of this ELISA was $1.0 \mathrm{pg} / \mathrm{mL}$. Coefficients of variation for intraassay and interassay replicates were less than $5.8 \%$ and $8.1 \%$, respectively. Recovery of IL-10 from serum was $100.0 \pm 12.9 \%$ (mean \pm SD). Detectable levels of IL-10 that always followed the standard curve were determined by sample titration. The results of this IL-10 assay correlated strongly with those determined using a previously established ELISA [19] (DNAX Research Institute, Palo Alto, Calif, USA) $(n=20, r=0.9729, P<.0001)$ and a commercially available ELISA kit (Biosource International, Camarillo, Calif, USA $)(n=42, r=0.9874, P<.0001)$.

\section{Determination of IL-6 and other laboratory parameters}

Serum concentrations of IL- 6 were measured using ELISA (SRL Inc, Tokyo, Japan) as previously described [20-22]. The lower limit of detection for IL-6 was $4.0 \mathrm{pg} / \mathrm{mL}$. Assay of Creactive protein (CRP) was performed using laser nephelometry (normal range, < $350 \mathrm{ng} / \mathrm{mL}$ ) (Hoechst Japan, Tokyo, Japan). Total leukocyte counts, hemoglobin concentrations, platelet counts, and erythrocyte sedimentation rates were determined using standard procedures.

\section{Gel filtration analysis}

Chromatographic procedures were performed using a fast protein liquid chromatography (FPLC) system (Pharmacia, Sollentuna, Sweden). Serum sample or recombinant human IL-10 was fractionated by gel filtration through a Superose 12 HR 10/30 column equilibrated with $50 \mathrm{mM}$ phosphate buffer, $\mathrm{pH} 7.2$, and $150 \mathrm{mM} \mathrm{NaCl}$. Each sample $(20 \mu \mathrm{L})$ was eluted with buffer at the rate of $0.4 \mathrm{~mL} / \mathrm{min}$. Fractions of $0.5 \mathrm{~mL}$ were collected, and immunoreactive IL-10 levels in each fraction were measured using ELISA. The column was calibrated with marker proteins of known molecular weight.

\section{Statistics}

Data were analyzed using the Mann-Whitney $U$ test and the Spearman rank correlation coefficient. Differences were considered significant at $P<.05$.

\section{RESULTS}

Figure 1 shows serum concentrations of CRP, IL-6, and IL10 in 62 patients with UC, 43 patients with CD, 25 patients with other colitides, and 44 normal control subjects. As shown in Figures 1(a) and 1(b), serum concentrations of CRP and IL-6 were increased in patients with active UC (CRP, $P<.0001$; IL-6, $P<.0001$ ) and active CD (CRP, $P<.0001$; IL-6, $P<.0001)$ compared with normal control subjects. Patients with active disease had a higher concentration of CRP (UC, $P=.0004$; CD, $P<.0001$ ) and IL-6 (UC, $P<.0001$; CD, $P<.0001$ ) than those with inactive disease. In patients with active disease, CRP concentrations were higher in patients with CD than in those with UC $(P<.0038)$, whereas IL-6 concentrations were comparable between UC and CD $(P=.0973)$. As shown in Figure 1(c), serum IL-10 concentrations were increased in those with active UC $(P=.0086)$ but not with active CD $(P=.07663)$ when compared with normal control subjects; the concentrations were higher in patients with active UC than with 


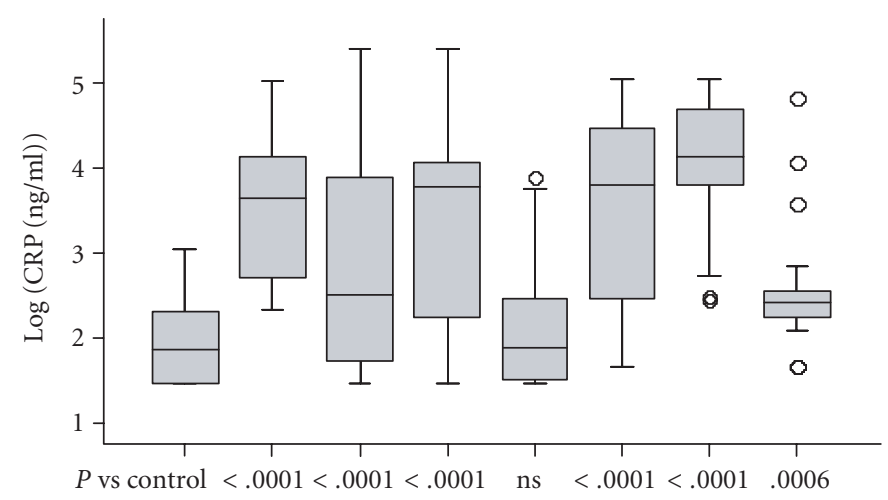

(a)

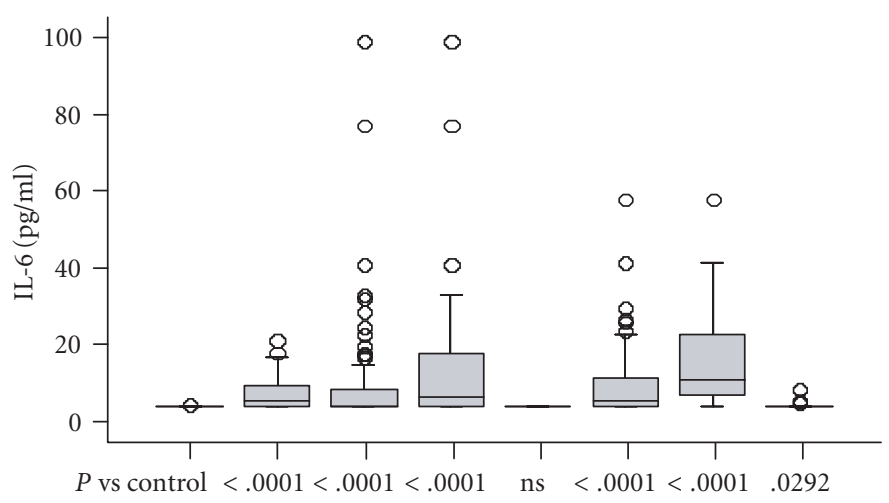

(b)

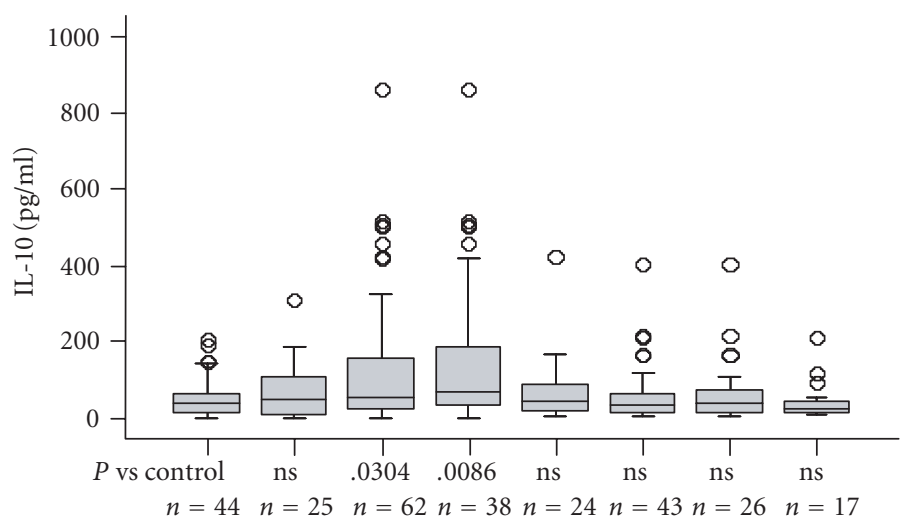

$\begin{array}{lccc}\text { Normal } & \text { Other } \\ \text { controls } & \text { colitides }\end{array} \quad \frac{\text { Total active inactive }}{\text { UC }} \quad \frac{\text { Total active inactive }}{\mathrm{CD}}$

(c)

FIGURE 1: Serum concentrations of CRP (a), IL-6 (b), and IL-10 (c) in patients with ulcerative colitis (UC), Crohn's disease (CD), other colitides and normal control subjects. The bars indicate the median \pm 25 percentile. The lower bar indicates the 10 th percentile, and the upper bar the 90th percentile. ns: not significant, $n$ : number of patients. Concentrations of CRP are shown on a logarithmic scale (vertical axis).

active CD $(P=.0338)$. No statistical association was observed between the concentration of IL-10 and clinical disease severity and activity or laboratory parameters, including serum IL-6, CRP, erythrocyte sedimentation rates, or total leukocyte counts (data not shown). Also, there were no significant differences in IL-10 concentrations between patients with and without steroid therapy regardless of the disease activity (data not shown). 


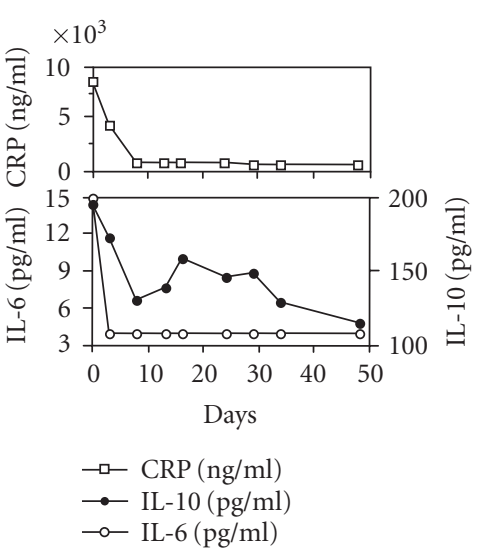

(a)

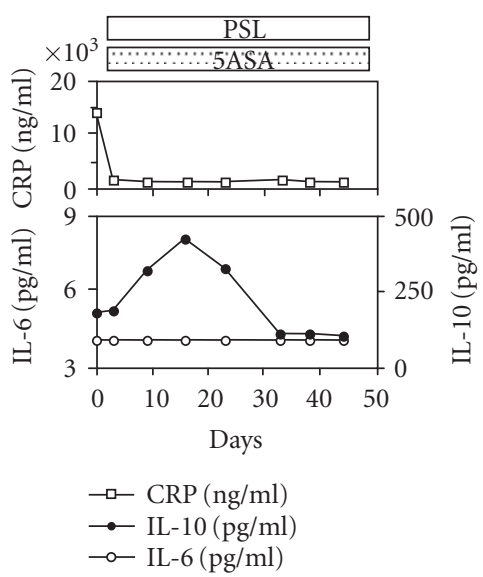

(b)

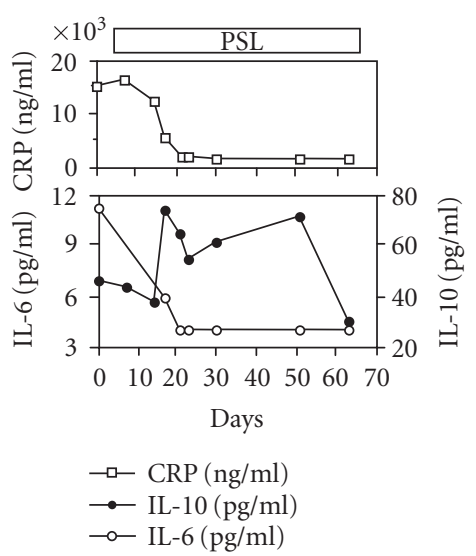

(c)

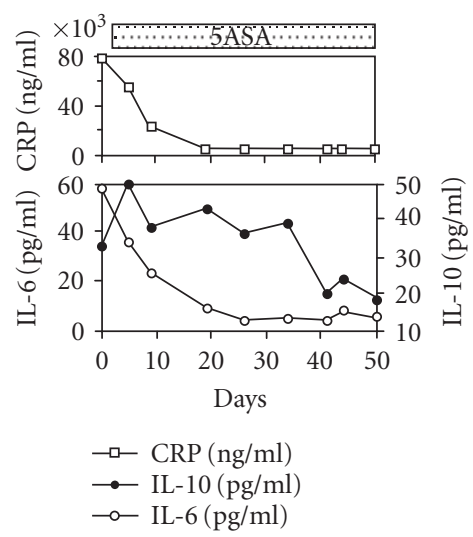

(d)

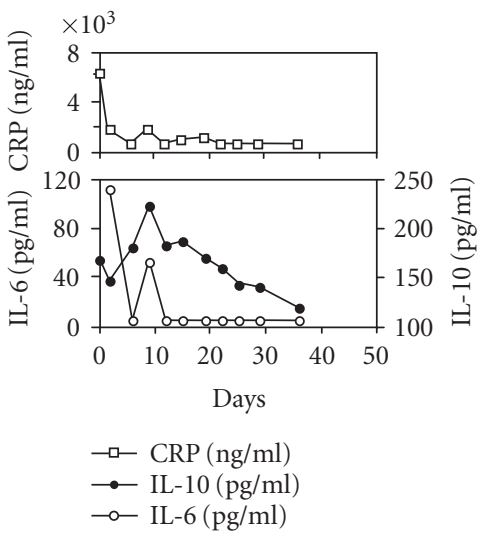

(e)

FIGURE 2: Time course of serum CRP, IL-6, and IL-10 concentrations in three patients with ulcerative colitis (UC) ((a)-(c)) and two with Crohn's disease (CD) ((d), (e)). (a) A 17-year-old woman with UC who had total colonic involvement receiving total parenteral nutrition. (b) A 17-year-old man with UC who had total colonic involvement treated with both 5-aminosalicylate and prednisolone (40-20 mg daily). (c) A 24-year-old man with UC who had total colonic involvement treated with prednisolone (40-15 mg daily). (d) A 21-year-old man with CD who had colonic involvement treated with 5-aminosalicylate. (e) A 36-year-old woman with CD who had ileocolitis and received nutrition therapy only. 5ASA: 5-aminosalicylate; PSL: prednisolone.

Figure 2 shows the time course of serum IL-10 and proinflammatory parameters, CRP and IL-6, followed longitudinally in three patients with UC and two patients with CD. Eventually, disease activity in all five patients was controlled by the treatment. In these cases, serum concentrations of IL-6 and CRP increased during the acute phase and returned to normal as patients went into remission. It should be noted that increased concentrations of IL-10 were consistently found as the disease began to resolve regardless of the treatment modality, and declined thereafter when the disease achieved stable remission.

The representative elution profiles of IL-10 immunoreactivities in sera from patients with IBD are shown in Figure 3. A substantial proportion of serum IL-10 is eluted in the similar fractions regardless of the disease activity. Sizing with molecular mass standards revealed the largest peak to be approximately $45 \mathrm{kDa}$, consistent with the predicted molecular mass for a recombinant human IL-10 dimer. Also, there were additional small peaks that eluted higher molecular weight form.

\section{DISCUSSION}

Many of the pathologic and clinical features of IBD reflect the effects of key cytokines essential to sustain inflammation [3-5]. In the present investigation, we focused on the levels of circulating immunoregulatory cytokine IL-10 in patients with intestinal inflammation. There have been some reports concerning serum IL-10 in patients with IBD. Kucharzik et al measured serum IL-10 concentrations in 44 patients with UC, 40 patients with CD, and 30 healthy control subjects. Increased IL-10 concentrations were seen in patients with both active UC and active CD compared with healthy control subjects [23]. Nielsen et al reported that serum IL-10 


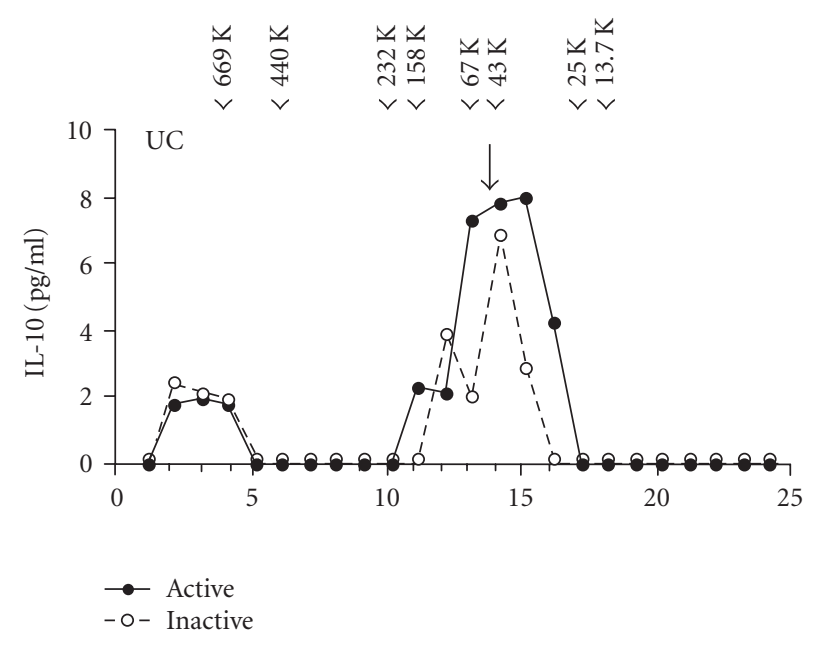

(a)

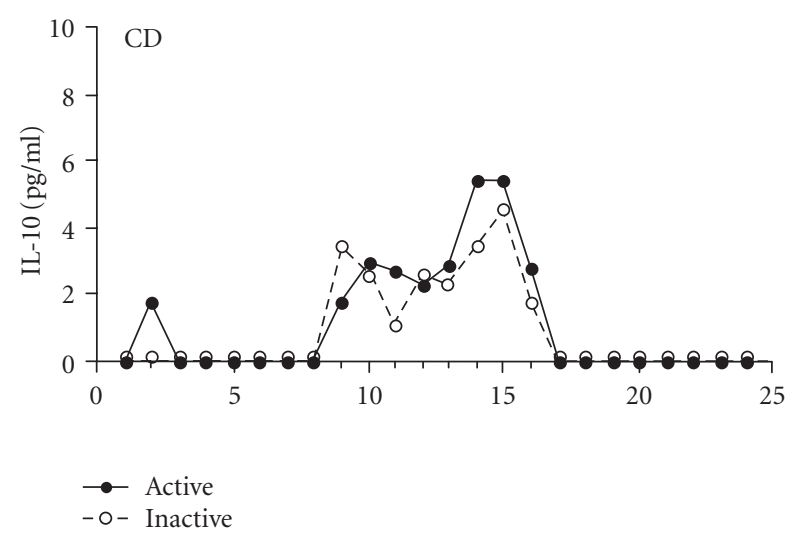

(b)

FIgURe 3: Fractionation of serum by FPLC gel filtration chromatography. A representative elution profile of a patient with ulcerative colitis (UC) and Crohn's disease (CD) is presented. Fractions were assayed for IL-10 concentrations by ELISA. The points represent the mean of duplicate analyses. The elution profiles of the molecular markers thyroglobulin $(669 \mathrm{kDa})$, ferritin $(440 \mathrm{kDa})$, catalase $(232 \mathrm{kDa})$, aldlase $(158 \mathrm{kDa})$, BSA $(67 \mathrm{kDa})$, ovalbumin $(43 \mathrm{kDa})$, chymotrypsinogen A $(25 \mathrm{kDa})$, and ribonuclease $\mathrm{A}(13.7 \mathrm{kDa})$ are indicated by arrow heads. The single peak corresponding to recombinant human IL-10 is marked by the arrow.

concentrations did not differ among UC $(n=20)$, CD $(n=14)$, and healthy control subjects $(n=22)[24]$. Our large scale study (UC, $n=62$; CD, $n=43$; healthy control subjects, $n=44$ ) showed the increase in serum IL-10 in patients with active UC but not in those with CD, as well as in patients with other forms of colitis and normal control subjects. This result is not simply because of lower inflammatory reaction in our CD population because CRP concentrations were higher in patients with CD than in those with UC. Our serum data are inconsistent with previous reports of increased tissue levels of IL-10 mRNA exclusively in UC but not in CD [24]. The different profile of IL-10 in these two diseases reported may result in variable manifestations between the two types of IBD: activating signals, responding cells, and related pathogenic events may be different in both diseases.

We next compare the serum IL-10 level with clinical and laboratory parameters of the disease activity during the course of disease. During the active disease, serum concentrations of IL- 6 and CRP increased and returned to normal as patients went into remission, similar to the previous reports [20-22, 25]. Notably, we found a different pattern with serum IL-10: in individual patients with both forms of IBD it gradually increased with the clinical resolution of disease but declined thereafter regardless of the treatment modality. Very similar results have been described with another immunoregulatory cytokine-soluble gp130, a soluble component of the IL- 6 receptor complex-showing a gradual increase in serum concentrations during the recovery phase rather than the very acute phase in the same diseases [26]. The significance of the delayed increase in these cytokines is unclear. However, it is plausible that this phenomenon may contribute to the systemic downregulation of the acute inflammatory process. Furthermore, this delayed increase implies that the contradictory results of serum IL-10 concentrations in IBD reported previously $[23,24]$ may depend on subtle differences in the phase of disease. We must keep in mind that the timing of cytokine measurement during the course of disease is a critical factor detecting the changes in cytokine levels, especially those with immunoregulatory activities. Even though the role of serum IL-10 in IBD is not fully understood, its serial measurement may help determine disease prognosis and confirm treatment efficacy.

Glucocorticoid is regarded as one of the powerful pharmacological modulators of cytokine production [27]. Somewhat surprisingly, we could not find statistical differences in serum IL-10 concentrations between IBD patients with and without steroid therapy. A time course of these patients also showed that ongoing treatment with steroids and 5aminosalicylate did not seem to affect serum IL-10 levels. Although it has become clear that glucocorticoids boost IL-10 production in vitro, there is no direct evidence regarding the in vivo effect of glucocorticoids on the production of IL-10 [27]. However, our data indicate that serum IL-10 level may reflect the inflammatory response related to the disease itself rather than the therapeutic effect per se in IBD patients.

Our understanding of the mucosal immune response in IBD suggests that immunotherapeutic drugs may be designed rationally by targeting specific steps in the pathway of immune activation. There is now widespread appreciation that proinflammatory cytokines such as IL-1, IL-6, IL8 , IL-12, or TNF- $\alpha$ play a predominant role in immune and inflammatory reactions in patients with IBD [3-6]. Moreover, previous data $[28,29]$ show that the level of IL-1 receptor antagonist, a natural antagonist of IL-1 [30], is not 
proportionally increased in IBD mucosa, and this imbalance of IL-1 and IL-1 receptor antagonist may lead to persistent inflammation. Interestingly, IL-10 has the capacity to inhibit proinflammatory cytokines while stimulating IL-1 receptor antagonist in vitro [8]. These data support the belief that IL-10 and related molecules may be therapeutic. Although a preliminary study of IL-10 in patients with active CD suggested benefit [31], subsequent trials failed to demonstrate efficacy [32, 33]. Recently, novel alternative therapeutic approaches, including the use of genetically modified Lactococcus lactis, gelatine microspheres containing IL-10, adenoviral vectors encoding IL-10, and combining regulatory $\mathrm{T}$ cells, have caused a significant reduction in intestinal inflammation in different mouse models [34], and they might be useful for treatment of human IBD.

Next we observed the elution profile of serum IL-10 by gel filtration to elucidate the structure of its circulating form. We found that serum IL-10 may exist predominantly as a dimer regardless of the disease status. Thus, circulating IL10 may be biologically active because this form of IL-10 can bind specifically to its receptor [35]. There is also a small amount of higher molecular weight form of circulating IL10 , most likely representing an aggregated form or a complex with other molecules, similar to what has been described for other cytokines $[22,26]$. To our knowledge, the present report is the first demonstration of the molecular weight and form of circulating IL-10 in patients with IBD.

In conclusion, the present study shows that serum IL-10 is increased during disease recovery in patients with IBD, and could be a valuable marker in monitoring disease status.

\section{REFERENCES}

[1] Podolsky DK, Fiocchi C. Cytokines, chemokines, growth factors, eicosanoids, and other bioactive molecules in inflammatory bowel disease. In: Kirsner JB, ed. Inflammatory Bowel Disease. 5th ed. Philadelphia, Pa: W.B.Saunders; 2000:191-207.

[2] Cominelli F, Arseneau KO, Pizarro TT. The mucosal inflammatory response. Cytokines and chemokines. In: Targan SR, Shanahan F, Karp LC, eds. Inflammatory Bowel Disease: From Bench to Bedside. 2nd ed. Dordrecht, The Netherland: Kluwer Academic; 2003:147-176.

[3] Shanahan F, Targan SR. Mechanisms of tissue injury in inflammatory bowel disease. In: Targan SR, Shanahan F, eds. Inflammatory Bowel Disease: From Bench to Bedside. Baltimore, Md: Williams \& Wilkins; 1994:78-88.

[4] Katz JA, Itoh J, Fiocchi C. Pathogenesis of inflammatory bowel disease. Current Opinion in Gastroenterology. 1999;15(4):291297.

[5] Podolsky DK. Inflammatory bowel disease (first of two parts). New England Journal of Medicine. 1991;325(13):928-937.

[6] Isaacs KL, Sartor RB, Haskill S. Cytokine messenger RNA profiles in inflammatory bowel disease mucosa detected by polymerase chain reaction amplification. Gastroenterology. 1992; 103(5):1587-1595.

[7] Fiorentino DF, Bond MW, Mosmann TR. Two types of mouse T helper cell. IV. Th2 clones secrete a factor that inhibits cytokine production by Th1 clones. Journal of Experimental Medicine. 1989;170(6):2081-2095.

[8] Howard M, O'Garra A. Biological properties of interleukin 10. Immunology Today. 1992;13(6):198-200.
[9] Fiorentino DF, Zlotnik A, Mosmann TR, Howard M, O'Garra A. IL-10 inhibits cytokine production by activated macrophages. Journal of Immunology. 1991;147(11):38153822.

[10] de Waal Malefyt R, Abrams J, Bennett B, Figdor CG, de Vries JE. Interleukin 10(IL-10) inhibits cytokine synthesis by human monocytes: an autoregulatory role of IL-10 produced by monocytes. Journal of Experimental Medicine. 1991;174(5):1209-1220.

[11] Bogdan C, Paik J, Vodovotz Y, Nathan C. Contrasting mechanisms for suppression of macrophage cytokine release by transforming growth factor- $\beta$ and interleukin-10. Journal of Biological Chemistry. 1992;267(32):23301-23308.

[12] Andersson J, Nagy S, Bjork L, Abrams J, Holm S, Andersson $\mathrm{U}$. Bacterial toxin-induced cytokine production studied at the single-cell level. Immunological Reviews. 1992;(127):69-96.

[13] Kuhn R, Lohler J, Rennick D, Rajewsky K, Muller W. Interleukin-10-deficient mice develop chronic enterocolitis. Cell. 1993;75(2):263-274.

[14] Schreiber S, Heinig T, Thiele H-G, Raedler A. Immunoregulatory role of interleukin 10 in patients with inflammatory bowel disease. Gastroenterology. 1995;108(5):1434-1444.

[15] Truelove SC, Witts LJ. Cortisone in ulcerative colitis: final report on a therapeutic trial. British Medical Journal. 1955;2(4947):1041-1048.

[16] Myren J, Bouchier IAD, Watkinson G, Softley A, Clamp SE, de Dombal FT. The OMGE multinational inflammatory bowel disease survey 1976-1982. A further report on 2657 cases. Scandinavian Journal of Gastroenterology. 1984;19(suppl 95):1-27.

[17] de Dombal FT, Softley A. IOIBD report no. 1: observer variation in calculating indices of severity and activity in Crohn's disease. Gut. 1987;28(4):474-481.

[18] Honda M, Yamamoto S, Cheng M, et al. Human soluble IL-6 receptor: its detection and enhanced release by HIV infection. Journal of Immunology. 1992;148(7):2175-2180.

[19] Gotlieb WH, Abrams JS, Watson JM, Velu TJ, Berek JS, Martínez-Maza O. Presence of interleukin 10 (IL-10) in the ascites of patients with ovarian and other intra-abdominal cancers. Cytokine. 1992;4(5):385-390.

[20] Mitsuyama K, Sata M, Tanikawa K. Significance of interleukin6 in patients with inflammatory bowel disease. Gastroenterologia Japonica. 1991;26(1):20-28.

[21] Mitsuyama K, Sasaki E, Toyonaga A, et al. Colonic mucosal interleukin-6 in inflammatory bowel disease. Digestion. 1991; 50(2):104-111.

[22] Mitsuyama K, Toyonaga A, Sasaki E, et al. Soluble interleukin6 receptors in inflammatory bowel disease: relation to circulating interleukin-6. Gut. 1995;36(1):45-49.

[23] Kucharzik T, Stoll R, Lugering N, Domschke W. Circulating antiinflammatory cytokine IL-10 in patients with inflammatory bowel disease (IBD). Clinical and Experimental Immunology. 1995;100(3):452-456.

[24] Nielsen OH, Køppen T, Rüdiger N, Horn T, Eriksen J, Kirman I. Involvement of interleukin- 4 and - 10 in inflammatory bowel disease. Digestive Diseases and Sciences. 1996;41(9):1786-1793.

[25] Mahida YR, Kurlac L, Gallagher A, Hawkey CJ. High circulating concentrations of interleukin-6 in active Crohn's disease but not ulcerative colitis. Gut. 1991;32(12):1531-1534.

[26] Mitsuyama K, Tomiyasu N, Suzuki A, et al. A form of circulating interleukin-6 receptor component soluble gp130 as a potential interleukin-6 inhibitor in inflammatory bowel disease. Clinical and Experimental Immunology. 2006;143(1):125-131. 
[27] Zhou X, Schmidtke P, Zepp F, Meyer CU. Boosting interleukin-10 production: therapeutic effects and mechanisms. Current Drug Targets: Immune, Endocrine \& Metabolic Disorders. 2005;5(4):465-475.

[28] Nishiyama T, Mitsuyama K, Toyonaga A, Sasaki E, Tanikawa K. Colonic mucosal interleukin 1 receptor antagonist in inflammatory bowel disease. Digestion. 1994;55(6):368-373.

[29] Casini-Raggi V, Kam L, Chong YJT, Fiocchi C, Pizarro TT, Cominelli F. Mucosal imbalance of IL-1 and IL-1 receptor antagonist in inflammatory bowel disease: a novel mechanism of chronic intestinal inflammation. Journal of Immunology. 1995;154(5):2434-2440.

[30] Dinarello CA, Thompson RC. Blocking IL-1: interleukin 1 receptor antagonist in vivo and in vitro. Immunology Today. 1991;12(11):404-410.

[31] van Deventer SJH, Elson CO, Fedorak RN. Multiple doses of intravenous interleukin 10 in steroid-refractory Crohn's disease. Crohn's disease study group. Gastroenterology. 1997; 113(2):383-389.

[32] Fedorak RN, Gangl A, Elson CO, et al. Recombinant human interleukin 10 in the treatment of patients with mild to moderately active Crohn's disease. The interleukin 10 inflammatory bowel disease cooperative study group. Gastroenterology. 2000;119(6):1473-1482.

[33] Schreiber S, Fedorak RN, Nielsen OH, et al. Safety and efficacy of recombinant human interleukin 10 in chronic active Crohn's disease. Crohn's disease IL-10 cooperative study group. Gastroenterology. 2000;119(6):1461-1472.

[34] Li M-C, He S-H. IL-10 and its related cytokines for treatment of inflammatory bowel disease. World Journal of Gastroenterology. 2004;10(5):620-625.

[35] Zdanov A. Structural features of the interleukin-10 family of cytokines. Current Pharmaceutical Design. 2004;10(31):38733884. 


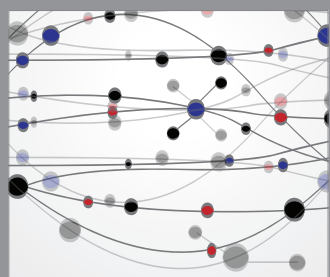

The Scientific World Journal
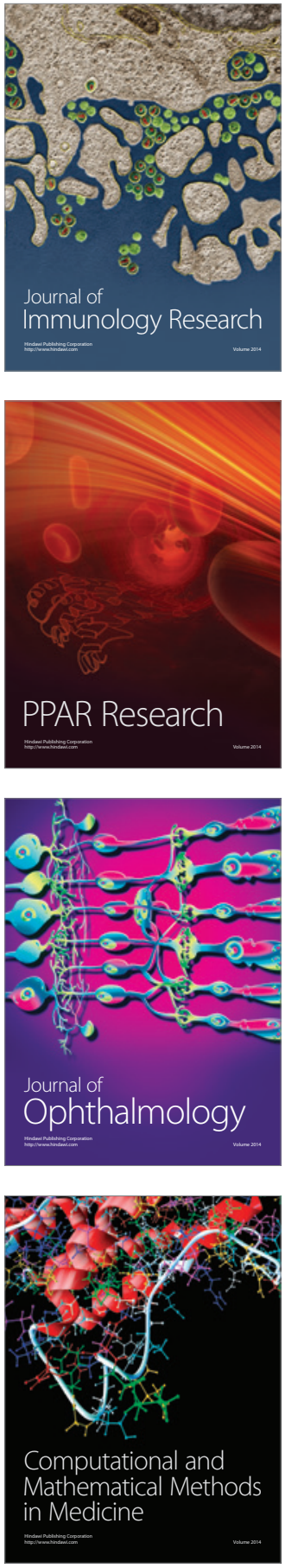

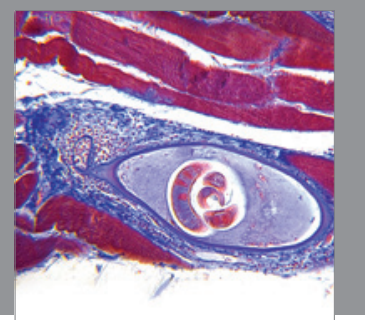

Gastroenterology

Research and Practice
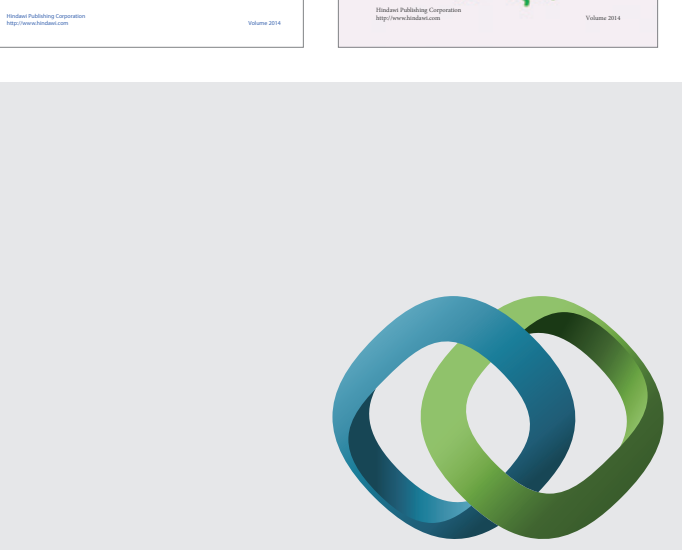

\section{Hindawi}

Submit your manuscripts at

http://www.hindawi.com
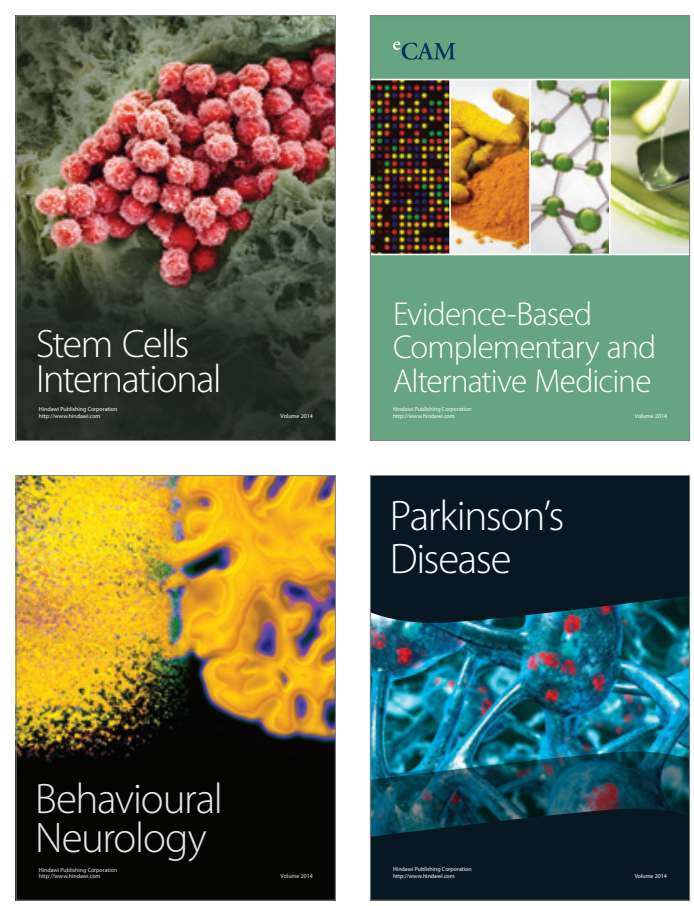

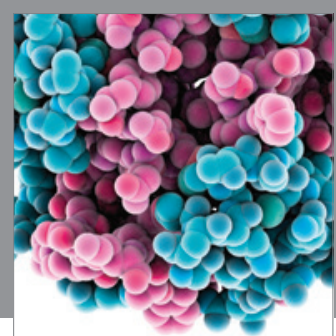

Journal of
Diabetes Research

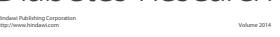

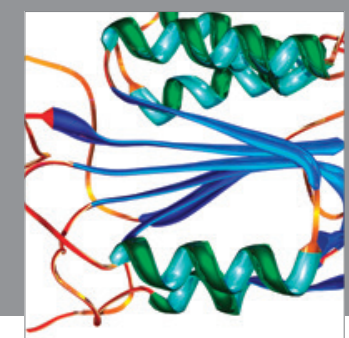

Disease Markers
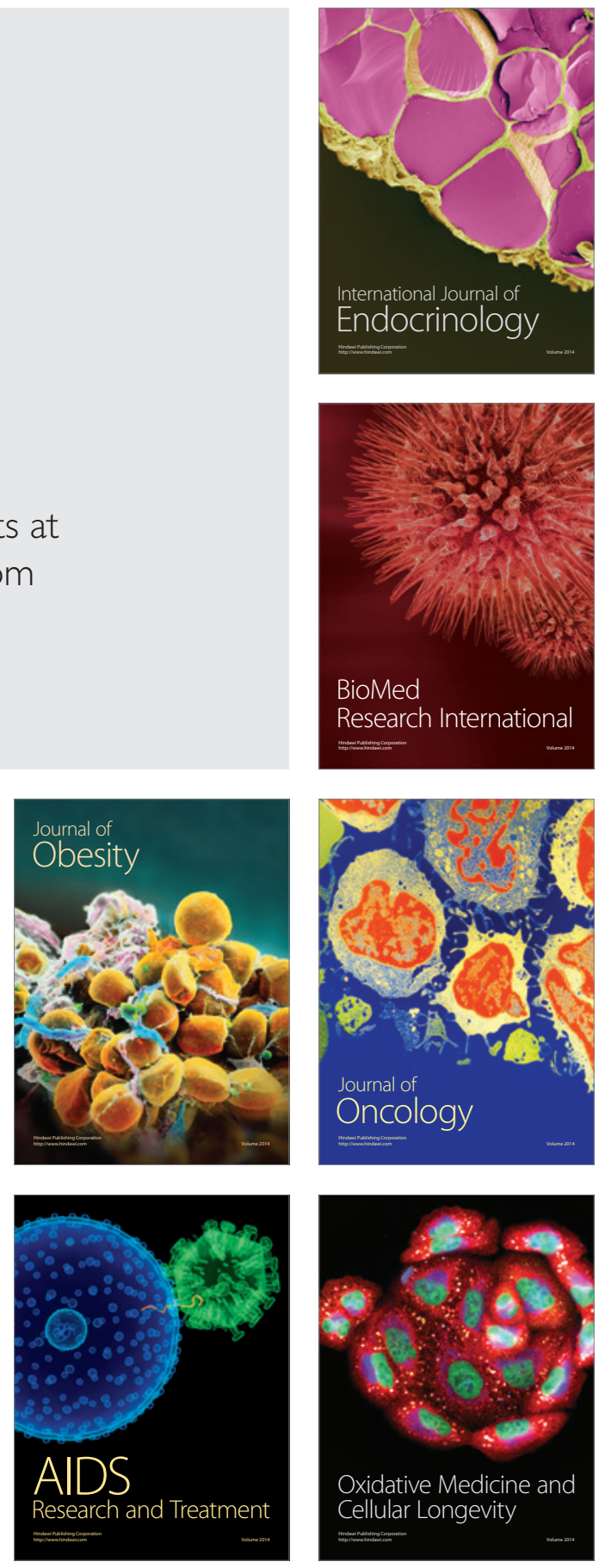